\title{
Multidisciplinary management of liver metastases in patients with colorectal cancer: a consensus of SEOM, AEC, SEOR, SERVEI, and SEMNIM
}

\author{
R. Vera ${ }^{1}$ (1) E. González-Flores ${ }^{2} \cdot$ C. Rubio ${ }^{3} \cdot$ J. Urbano $^{4} \cdot$ M. Valero Camps $^{5} \cdot$ J. J. Ciampi-Dopazo ${ }^{6} \cdot$ J. Orcajo Rincón $^{7}$. \\ V. Morillo Macías ${ }^{8}$. M. A. Gomez Braco ${ }^{9}$. G. Suarez-Artacho ${ }^{9}$
}

Received: 12 April 2019 / Accepted: 8 July 2019 / Published online: 29 July 2019

(c) The Author(s) 2019

\begin{abstract}
Colorectal cancer (CRC) has the second-highest tumor incidence and is a leading cause of death by cancer. Nearly $20 \%$ of patients with CRC will have metastases at the time of diagnosis, and more than $50 \%$ of patients with CRC develop metastatic disease during the course of their disease. A group of experts from the Spanish Society of Medical Oncology, the Spanish Association of Surgeons, the Spanish Society of Radiation Oncology, the Spanish Society of Vascular and Interventional Radiology, and the Spanish Society of Nuclear Medicine and Molecular Imaging met to discuss and provide a multidisciplinary consensus on the management of liver metastases in patients with CRC. The group defined the different scenarios in which the disease can present: fit or unfit patients with resectable liver metastases, patients with potential resectable liver metastases, and patients with unresectable liver metastases. Within each scenario, the different strategies and therapeutic approaches are discussed.
\end{abstract}

Keywords Colorectal cancer $\cdot$ Liver metastases $\cdot$ Surgery $\cdot$ Chemotherapy $\cdot$ Locoregional therapies $\cdot$ Consensus

R. Vera

ruth.vera.garcia@cfnavarra.es

1 Medical Oncology, Complejo Hospitalario de Navarra, Calle Irunlarrea, 3, 31008 Pamplona, Navarra, Spain

2 Medical Oncology, Hospital Virgen de Las Nieves, Granada, Spain

3 Radiation Oncology Department, University Hospital HM Sanchinarro, Madrid, Spain

4 Vascular and Interventional Radiology, Vithas Hospitals Group, Madrid, Spain

5 Nuclear Medicine, Clínica Rotger (Quiron Salud), Palma de Mallorca, Spain

6 Interventional Radiology Unit, Complejo Hospitalario de Toledo, Toledo, Spain

7 Nuclear Medicine, Hospital General Universitario Gregorio Marañón, Madrid, Spain

8 Radiation Oncology, Hospital Provincial de Castellón, Castellón, Spain

9 Hepatobiliary and Liver Transplantation Unit, University Hospital Virgen del Rocío, Sevilla, Spain

\section{Introduction}

Colorectal cancer (CRC) has the second-highest tumor incidence and is a leading cause of death by cancer $[1,2]$. Nearly $20 \%$ of patients with CRC will have metastases at the time of diagnosis, and more than $50 \%$ of patients with CRC develop metastatic disease during the course of their disease (15-25\% synchronously and 50-60\% metachronously) [3].

In the past, palliative chemotherapy showed dismal 5-year survival rates of less than $5 \%$ in these patients, but clinical advances with new chemotherapeutic and targeted biological agents have reached median survival of almost 30 months [4]. Although metastases are generally widely disseminated, a minimal metastatic disease described as an "oligometastatic or oligo-recurrence state" [5] is relatively common in these patients, showing a clinical scenario in which the combination of systemic and local therapies improves overall survival. Although the number of metastases accepted as oligometastases that would benefit from local treatment is not well established, the change in prognosis of these patients has been reflected in the 8th AJCC staging (M1a: metastases at one site, M1b: metastases at two or more sites). 

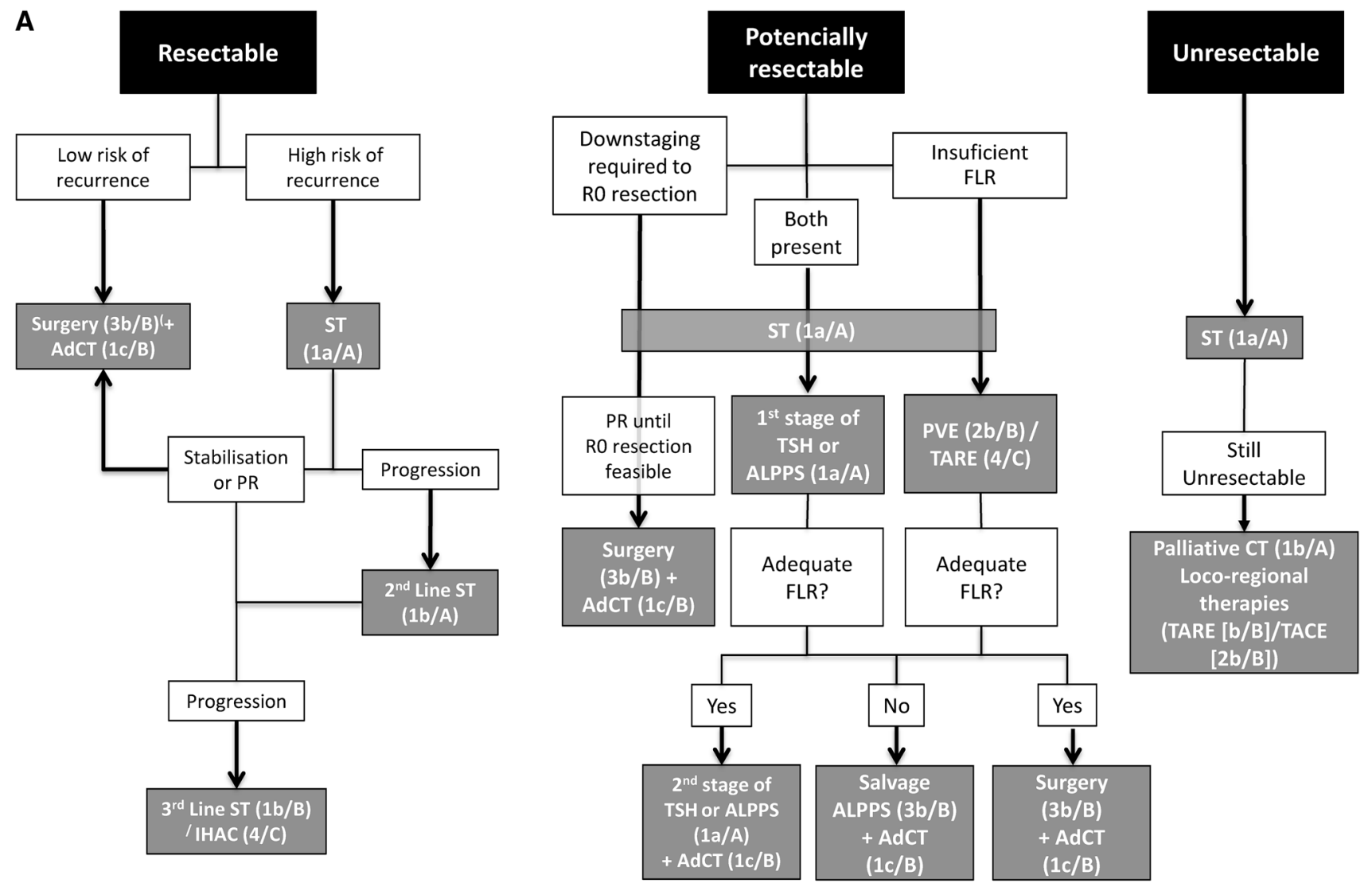

B

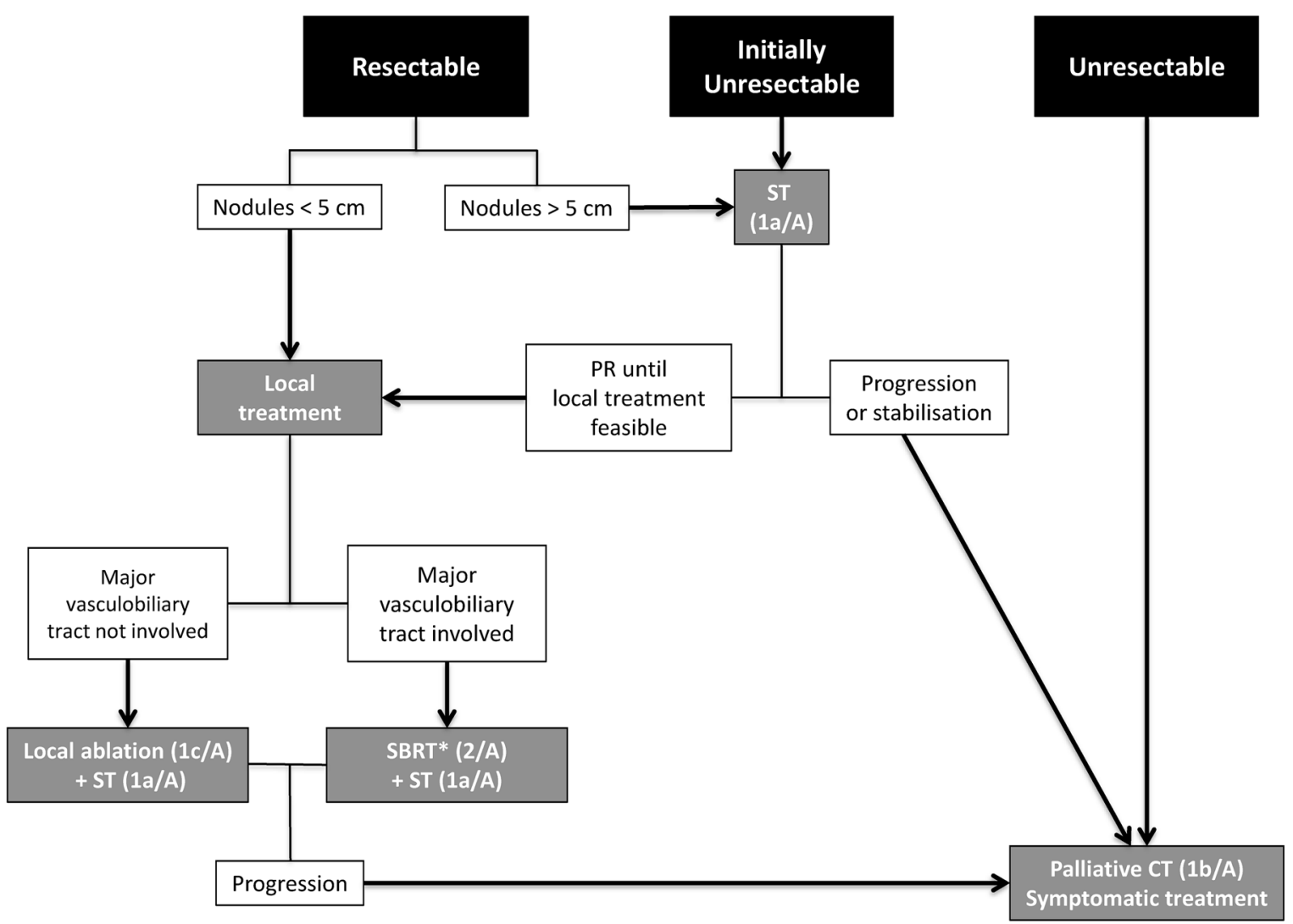


४Fig. 1 Algorithm for the management of liver metastases in patients with colorectal cancer. a Fit patients. b Unfit patients. AdCT adjuvant chemotherapy, ALPPS associated liver partition and portal vein ligation for stage hepatectomy, FLR future liver remnant, $N C T$ neoadjuvant chemotherapy, $P R$ partial response, $S B R T$ stereotactic body radiation therapy, $S T$ systemic therapy, TACE transarterial chemoembolization, TARE transarterial radioembolization, TSH two-stage hepatectomy. Between brackets appear the level of evidence/grade of recommendation according to the Oxford Centre for Evidence-based Medicine Levels of Evidence (March 2009): level of evidence: (1a) SR (with homogeneity) of RCTs; (1b) individual RCT (with narrow confidence interval); 1c, all or none\$; (2a) SR (with homogeneity) of cohort studies; (2b) individual cohort study (including low-quality RCT; e.g., $<80 \%$ follow-up); (2c) "Outcomes" research or ecological studies; (3a) SR (with homogeneity) of case-control studies; (3b) individual case-control study; (4) case-series (and poor quality cohort and case-control studies); (5) expert opinion without explicit critical appraisal, or based on physiology, bench research or "first principles". Grade of the recommendation: (A) consistent level 1 studies; (B) consistent level 2 or 3 studies or extrapolations from level 1 studies; (C) level 4 studies or extrapolations from level 2 or 3 studies; (D) level 5 evidence or troublingly inconsistent or inconclusive studies of any level

In selected favorable patients who are medically operable and who have resectable liver metastases, surgery with curative intent has reached high rates of local control and prolonged survival [5-year overall survival $(\mathrm{OS})>50 \%$ ] [6]. This is why the approach to patients with liver metastatic CRC is a highly important challenge. Multidisciplinary committee implementation has been one of the most relevant aspects. The first step in the treatment of these patients is to clearly define if we are dealing with a resectable disease or if it would be resectable after systemic treatment, as well as primary tumor management in cases of synchronous metastatic. Based on these findings, first-line treatment will be defined. If, conversely, the disease is clearly unresectable, the choice of treatment remains in the hands of the medical oncologist.

A group of experts from the Spanish Society of Medical Oncology (SEOM), the Spanish Association of Surgeons (AEC), the Spanish Society of Radiation Oncology (SEOR), the Spanish Society of Vascular and Interventional Radiology (SERVEI), and the Spanish Society of Nuclear Medicine and Molecular Imaging (SEMNIM) met to discuss and provide a multidisciplinary consensus on the management of liver metastases in patients with CRC. In this consensus, we will define the different scenarios in which the disease can present, as well as the different strategies and therapeutic approaches that can be offered to these patients.

\section{Colorectal liver metastases detection}

Knowing the number, size, and location, as well as the main biliary and vessel relationships, of CRC liver metastases $(\mathrm{CRClm})$ is mandatory before treatment planning.
Additionally, presurgical neoadjuvant responses and liver volumetry must be taken into account. Imaging techniques include computed tomography (CT), magnetic resonance (MR), positron emission tomography (PET) and ultrasound. The best methods for CRClm detection are CT and MR [7]. CT with a multiphasic technique and optimal scanning parameters providing high contrast and spatial resolution should be the initial imaging tests. On CT, liver metastases are hypodense on portal and delayed phases. CT is indicated for the detection of lung metastases. Preoperatively, both CT and MR are indistinct [8]. For subcentimetric liver nodules and after neoadjuvant chemotherapy, MR is superior to CT [9]. T2 gradient echo, diffusion sequences and hepatobiliary-specific MR contrast medium are useful in the characterization of small size lesions and to make differential diagnoses. Ultrasound improves disease detection sensitivity with ultrasound contrast introduction. US is useful to guide percutaneous ablations and is also an important tool during surgical removal [10]. PET-CT compared with CT alone does not result in frequent changes in surgical management [11]. The role of PET/CT in CRClm detection is to rule out extrahepatic disease, thus allowing the evaluation of the resectability of a given metastatic lesion and consequently modifying the management of approximately $24 \%$ of patients in this setting [12-16].

\section{Resectable liver metastases}

\section{Fit patients (Fig. 1a)}

Surgical resection is widely recognized as the gold standard treatment of resectable CRClm. However, this one lacks a high level of evidence, because it was considered unethical to design randomized studies with a non-surgical patient arm. Resectable CRClm are defined as metastatic liver disease in which a R0 resection can be performed, leaving at least $20-25 \%$ of total liver volume with adequate inflow, outflow and biliary drainage [17]. This definition encompasses a wide range of patients. From those with peripheral single metastases that are easily resectable to those with high tumor burden or even those with single metastasis but located hepatic-center that require a major hepatectomy.

Surgical resection is widely recognized as the gold standard treatment for resectable CRClm. However, this strategy lacks a high level of evidence because it was considered unethical to design randomized studies with a nonsurgical patient arm. Resectable CRClm are defined as metastatic liver disease for which an $\mathrm{R} 0$ resection can be performed, leaving at least $20-25 \%$ of the total liver volume with adequate inflow, outflow and biliary drainage [17]. This definition encompasses a wide range of patients. From those with a single, peripheral metastasis that is easily resectable to 
those with high tumor burden or even those with a single metastasis that is located at the hepatic center and requires a major hepatectomy.

Several authors have tried to identify preoperative factors of poor prognosis to predict survival or even use them as a tool for treatment selection. These factors include tumor at stage T3-T4, tumor burden ( $\geq 3$ liver metastases or the largest liver metastasis is $\geq 5 \mathrm{~cm}$ in diameter), and synchronous CRLM and serum CEA level $\geq 5 \mathrm{ng} / \mathrm{ml}$ $[18,19]$. According to these factors, Zhu et al. [18] divided resectable patients into high- and low-risk patients. Among the high-risk patients, those who had received neoadjuvant chemotherapy (NCT) had a longer median overall survival (38.9 m vs. $28.4 \mathrm{~m}$ ) and a better 5-year OS (39\% vs. 33\%; $p=0.028$ ) than those of patients who had not received NCT. These differences regarding NCT were not observed among low-risk patients. Therefore, this classification allows the identification of resectable patients who benefit from NCT.

Previously, Fong et al. [20] established a clinical score for predicting recurrence after hepatic resection for metastatic colorectal cancer based on clinical and morphological criteria (size and number of liver metastases), as well as CEA levels. More recently, Margonis et al. [21] developed the GAME score, which presents some advantages over the FONG score. First, it is the first score to include a genetic criterion (K-RAS status). Furthermore, the GAME score incorporates the tumor burden score (TBS) as a morphological criterion; compared with the size and number of liver metastases, TBS has proved to be a powerful tool to calculate the impact of tumor morphology on long-term survival among patients with CRClm. In addition, while previous scores have been imprecise in identifying patients with poor prognosis, patients with a GAME score of 6-7 (high risk) had an expected 5-year survival rate of $0 \%$. Finally, when patients were classified as low, intermediate, and high risk by the GAME score, significant differences were found in the 5-year OS rate among the three groups of patients. However, when the FONG score was applied to the same cohort of patients, significant differences were found between patients with low and intermediate risks but not between those with intermediate and high risks. Therefore, the GAME score outperforms other scores to identify and discriminate between patients with intermediate- and highrisk CRClm.

\section{Low-risk resectable patients}

As mentioned earlier, NCT has not demonstrated a benefit; thus, these patients must directly undergo liver surgery. In most cases, low-risk patients are those with less tumor burden. So, the type of liver resection to perform will be minor hepatectomy (defined as less than 4-segment hepatectomy) [22] or limited parenchymal sparing hepatectomy
(PSH). The better prognosis of these cases is due to two main reasons:

- $R 0$ resection is easily performed To reach a $\mathrm{R} 0$ resection is considered the most important factor associated with better prognosis in terms of 5-year OS: $55 \%$ in R0 patients vs $26 \%$ in R1 patients; $p=0.017$ [23]. Multivariate analysis identified $\mathrm{R} 1$ resection $(p=0.03)$ as a factor independently associated with worse survival [24].

- Low-burden tumor The number and size of liver metastases negatively influence patient survival [18]. Most of these patients will undergo the following two types of liver resection:

Mainly due to the location of the lesions, a few low-risk patients will require major hepatectomies. These are associated with a higher risk (OR 1.642, CI 95\% 1.281-2.104, $p<0.001)$ and rate $(36.9 \%$ vs $24.3 \%, p<0.001)$ of severe morbidity as well as a higher risk (OR 2.561, CI 95\% $1.424-4.606, p=0.002)$ and rate $(7.4 \%$ vs $2.6 \%, \mathrm{p}<0.001)$ of mortality than minor hepatectomy.

Strategies based on PSH were initially described by Gold et al. [25], who demonstrated that multiple uni- or bilobar liver resections (wedge resections) respecting the uninvolved liver parenchyma have no negative impact on oncological outcomes if R0 resection is completed. Similar results were subsequently obtained by several authors in terms of diseasefree survival (DFS) and OS with lower rates of general complications ( 25 vs. $34 \% ; p=0.03$ ) and type Dindo-Clavien III-IV (10 vs. $16 \%, p=0.04$ ) when compared with standard or extent hepatectomies [26].

Other benefits of PSH include low liver failure and short intensive care unit-stays, a high rate of patients who receive adjuvant chemotherapy, and great preservation of uninvolved liver parenchyma to perform salvage re-hepatectomy in cases of liver recurrence.

\section{High-risk resectable patients}

These patients commonly have a high tumor burden, which is why these patients usually require a major hepatectomy (four or more segments) or an extensive bilobar PSH to obtain a $\mathrm{R} 0$ resection.

Although R0 resection could be initially performed, several authors have demonstrated that NCT improves 5-year overall survival. The benefits of NCT in this group of patients include the following:

- The size of CRClm is reduced, thus making liver resection easier.

- Chemotherapy is better tolerated in this setting.

- Micrometastatic disease is eradicated. 
- Chemosensitivity and patient tolerance is assessed preoperatively, providing valuable information on which postoperative regimen to use [27].

- Those patients who benefit from liver metastases surgery are identified. Five-year OS and disease-free survival are significantly worse in patients with progression after NCT even when a R0 resection is obtained (5-year OS in progression-patients reached $8 \%$ vs $30 \%$ in stabilizationpatients or $37 \%$ in partial-response-patients) [28]. Therefore, most groups consider that progression after NCT is a contraindication criterion for liver surgery.

A meta-analysis identified three randomized clinical trials comparing surgery alone to surgery plus systemic therapy [29]. The analysis showed a benefit of chemotherapy in progression-free survival (PFS) and DFS but not in OS. Another meta-analysis combined data on 1896 patients and found that perioperative chemotherapy improved DFS but not OS. Additional recent meta-analyses have also failed to observe an OS benefit with AT [30].

In low-risk resectable patients who have not received perioperative chemotherapy, there is no strong evidence to support the use of AT, whereas high-risk resectable patients may benefit from adjuvant therapy (AT). The international guidelines recommend AT after surgical resection of CRClm despite the low level of evidence. However, there is still no standard treatment, and the effectiveness of AT remains controversial. The preferred perioperative chemotherapy in resectable patients should be the combination of 5-fluorouracil, leucovorin, and oxaliplatin (FOLFOX) [or alternatively capecitabine with oxaliplatin (CAPOX)], as reported for the EPOC trial [31]. Biologics are not recommended in resectable liver metastases. EGFR-targeting monoclonal antibodies (cetuximab and panitumumab) are not to be used in this setting, based on the data from the new EPOC trial [32]. No data with bevacizumab are available for this specific patient group; therefore, bevacizumab should not be used.

\section{Unfit patients (Fig. 1b)}

Ablative treatments are a good alternative for patients who are technically resectable but inoperable due to poor clinical conditions or comorbidities. Percutaneous ablation should be reserved for patients who are not optimal candidates for resection or who are not willing to undergo surgery [33]. The objective of ablation in resectable patients is to achieve complete local control A0, equivalent to R0. A remarkable aspect of the ablative techniques is that they can be used together with any chemotherapy regimen or surgery without impending any pre, post or concomitant oncologic treatment [34]. Patients with a limited number of liver metastases can be treated with other less-invasive local treatments. Ablation treatment is performed by placing a probe under the image guide inside the tumor nodule. CT, ultrasound or cone beam CT can be used to precisely guide the puncture inside the tumor. Energy will be delivered locally through the probe to cause a predictable and controllable volume of tissue necrosis [35]. There are several ablative technologies available, including heat radiofrequency (RF) or microwaves (MW), cold (cryoablation) or electric pulses (irreversible electroporation [IRE]) [36] (Table 1). The common factor among ablation therapies is that they are less invasive than surgery, have a shorter recovery time and have fewer major complications [37]. RF, MW ablation, and more recently stereotactic body radiation therapy (SBRT) [38] are ablation therapies with minimal toxicity and good clinical results, providing an opportunity for curative intent to nonoperative patients. Currently, there are different ablation technologies available that can be applied percutaneously or intraoperatively that have demonstrated at least good local tumor control (LC) (Tables 2 and 3).

Although less invasive than surgery, normal liver function is required for all ablation techniques. Unlike surgery with ablation, it is impossible to have pathological confirmation of the results and to know in advance if the whole nodule has been effectively treated. Under general conditions, liver resection is superior to ablation in survival outcomes. Radiofrequency is the most commonly used thermal ablation therapy since the late 90 s and has shown as much

Table 1 Types of ablation therapies for colorectal liver metastases

\begin{tabular}{lllll}
\hline Treatment & Application & Energy & Image guide & Probes \\
\hline Radiofrequency & Percutaneous, open, laparoscopic & Heat & US, TC, CBCT & Single needle \\
Microwaves & Percutaneous, open, laparoscopic & Heat & US, TC, CBCT & Single needle \\
Cryotherapy & Percutaneous & Cold & CT & N3 needles \\
Irreversible electroporation & Percutaneous open & Nonthermal & CT, US & CT needles \\
Stereotactic body radiotherapy & Percutaneous & Radiotherapy & CT & Fiducial/s \\
High-intensity focused ultrasound & Percutaneous & Ultrasound & MR & No needles \\
\hline
\end{tabular}

$C T$ computed tomography, $C B C T$ cone beam CT, $M R$ magnetic resonance; US ultrasound 
Table 2 Evidence of ablation therapies for colorectal liver metastases

\begin{tabular}{lllll}
\hline Treatment & Invasive & Anesthesia & $\begin{array}{l}\text { Histologic } \\
\text { validation }\end{array}$ & Evidence \\
\hline Radiofrequency & Yes & Yes & Yes & Overall survival \\
Microwaves & Yes & Yes & No & Local control \\
Cryotherapy & Yes & Yes & No & No \\
Irreversible electroporation & Yes & Yes & No & No \\
Stereotactic body radiotherapy & No & No & No & Local control \\
High-intensity focused ultrasound & No & No & No & No \\
\hline
\end{tabular}

Table 3 Comparative safety and survival for ablation therapies

\begin{tabular}{|c|c|c|c|}
\hline Treatment & Indication/contraindication $^{\mathrm{a}}$ & Safety $^{\mathrm{b}}$ & Survival \\
\hline Radiofrequency & $\begin{array}{l}\text { Number of lesions is not an absolute con- } \\
\text { traindication. Size } \leq 3 \mathrm{~cm} \text {. Contraindicated } \\
\text { if central or less than } 1 \mathrm{~cm} \text { to colon }\end{array}$ & $\geq 6 \%$ grade 3 complications & 5 years $48.7-56 \%$ \\
\hline Microwaves & $\begin{array}{l}\text { Number of lesions is not an absolute con- } \\
\text { traindication. Size } \leq 5 \mathrm{~cm} \text {. Contraindicated } \\
\text { if central or less than } 1 \mathrm{~cm} \text { to colon }\end{array}$ & Similar to radiofrequency ablation & 3 years up to $78 \%$ \\
\hline Cryotherapy & 3 nodules $\leq 3 \mathrm{~cm}$ & $5.8 \%$ grade 3 complications & 3 years up to $60 \%$ \\
\hline Irreversible electroporation & Central/hilar nodule $\leq 3 \mathrm{~cm}$ & $15-18 \%$ grade 3 complications & Not clearly reported \\
\hline Stereotactic body radiotherapy & Depended on tumor volume & Not reported grade $\geq 3$ toxicity & 2 years up to $75 \%$ \\
\hline High-intensity focused ultrasound & Lesions size more than $3 \mathrm{~cm}$. Pain control & Limited experience & Not available \\
\hline
\end{tabular}

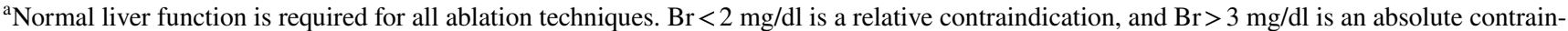
dication for any ablation technique in colorectal liver metastases

${ }^{b}$ Safety: Memorial Sloan-Kettering Cancer Complication Classification (see references). Based on the references [36, 37, 40, 87, 102-108]

as $94 \%$ of local control and $31 \%$-year OS when treated tumors are $\leq 3 \mathrm{~cm}$, centrally located and with ablation margins greater than $5 \mathrm{~mm}$ [39]. MW is a promising technology with some advantages over RF [40]. The indications for RF and $\mathrm{MW}$ are well-located tumors less than $5 \mathrm{~cm}$. Tumor number is not an absolute contraindication, but in most centers, the consensus is to treat up to five nodules [34, 41]. $\mathrm{Br}$ levels lower than $3 \mathrm{mg} / \mathrm{dl}$ and induced necrosis less than the volume equivalent to two segments are general rules to indicate RF or MW ablation. Factors that influence ablation success are size, location, visibility of the target tumor and RAS mutation. Evidence suggests that metastases $>3 \mathrm{~cm}$ are more likely to undergo incomplete ablation. Local tumor progression-free survival after ablation in mutant-RAS was significantly worse than wild type [39-42]. Blood vessels $>3 \mathrm{~mm}$ may cause dispersion in tissue heating. This is known as the 'heat-sink effect', and it is a limitation of RF that is overcome using MW. Centrally located metastases contraindicated RF or MW because of concern for main biliary tree complications. In those cases, IRE could be an option because this technology does not damage biliary or vascular structures [43].

Historically, radiation therapy has had a limited role in the treatment of liver metastases because of the risk of liver toxicity induced by high doses delivered to normal liver tissue. However, recent technological advances have contributed to the development of SBRT as a precise tightly focused radiation technique that allows the treatment of hepatic metastases with an ablative intent while significantly limiting the dose to the healthy liver and surrounding tissues. Liver SBRT requires the integration of imaging (CT, MRI, PET-CT) to properly define the metastases, highly conformed dosimetry to further minimize radiation dose in healthy tissues, and intrafraction control of the liver motion to deliver the dose to the metastases with accuracy [44]. The safety and effectiveness of SBRT have been evaluated with encouraging results in retrospective and prospective clinical studies of liver metastases, showing minimal toxicity, high rates of LC [45-53] and promising OS [52, 53].

The first results of SBRT published in 1995 showed the feasibility of the technique and 50\% LC [45]. Phase I studies reported the dose escalation benefit in a single fraction (14-26 Gy), reaching 66\% LC at 18-month [46]. A multicenter phase I/II study demonstrated the safety and efficacy of high doses of SBRT, $60 \mathrm{~Gy}$ in patients with 1-3 metastases, with a 2 -year LC of $92 \%(100 \%$ in lesions $<3 \mathrm{~cm})$ and $2 \%$ of grade 3 toxicity [48]. LC seems mainly influenced by size $(<5 \mathrm{~cm})$ and radiation dose (BED $>100 \mathrm{~Gy})$, 
and dose escalation appears to be particularly important in CRClm [48, 50]. When only dose-escalated regimens are analyzed, 1- and 2-year LC range from $90-100 \%$ and 81-100\%, respectively [47-49]; recent phase II studies with even higher doses (75 Gy in 3 fractions) have reported $91 \%$ 2-year LC and high OS (2-year OS of 70\%) [50].

SBRT is a very well-tolerated treatment with a low toxicity profile (G1-2 of 0-28\%), exceptionally severe toxicity and grade 3 late complications $<5 \%$. Long-term results with SBRT have also shown low toxicity (grade $3<5 \%$ ) and long survival times (3-year OS of 4\%) [52]. Although most of the studies have treated a limited number of liver metastases (1-3 lesions), patients with multiple liver metastases can be treated safely and can benefit from sequential SBRT with high LC (80.6\% and 65\% at 2 and 4 years) and prolonged survival (5-year OS of 57.6\%) [53].

A major limitation of SBRT for liver metastases is the lack of randomized studies comparing SBRT with other local techniques; however, retrospective and prospective studies show durable LC (Table 4). SBRT offers an alternative, noninvasive approach to the treatment of limited
CRClm in inoperable patients or those with unresectable metastases, especially in metastases greater than $3 \mathrm{~cm}$ or central lesions close to the main biliary tree or vascular structures that are not amenable to thermal ablation and have the fewest local therapeutic options. SBRT should also be studied in a multi-institutional setting in oligometastatic patients in combination with systemic therapies to improve overall survival.

\section{Potentially resectable liver metastases}

\section{Surgical strategy}

New surgical strategies and pharmacological agents have allowed an increase in the resectability of CRClm patients from $1-2 \%$ to $15-30 \%$.

These patients are defined as those who present the following situations.

Table 4 Outcomes of stereotactic body radiotherapy for liver metastases in prospective and retrospective studies

\begin{tabular}{|c|c|c|c|c|c|c|c|c|}
\hline Author & $\begin{array}{l}\text { Number of } \\
\text { patients/number } \\
\text { of lesions }\end{array}$ & $\begin{array}{l}\text { Number of } \\
\text { metastases per } \\
\text { patient/size }\end{array}$ & $\begin{array}{l}\text { Type of metas- } \\
\text { tases }\end{array}$ & $\begin{array}{l}\text { Follow-up } \\
\text { (months) }\end{array}$ & $\begin{array}{l}\text { Total dose (Gy) } \\
\text { number of frac- } \\
\text { tions (fx) BED }\end{array}$ & $\begin{array}{l}\text { Toxicity grade } \\
\text { (G) }\end{array}$ & $\mathrm{LC}$ & $\begin{array}{l}\text { Survival OS } \\
\text { median } S\end{array}$ \\
\hline $\begin{array}{l}\text { Herfarth et al. } \\
\text { [46] } \\
\text { Phase I-II }\end{array}$ & $37 / 56$ & $\begin{array}{l}1-3 \\
\leq 6 \mathrm{~cm}\end{array}$ & NR & 15.1 & $\begin{array}{l}14-26 \text { Gy } \\
(1 \mathrm{fx}) \\
\text { BED 34-94 Gy }\end{array}$ & No late $\geq \mathrm{G} 3$ & $\begin{array}{l}71 \%_{1 \mathrm{y}} \\
67 \%_{18 \mathrm{~m}}\end{array}$ & $\begin{array}{l}72 \%_{1 y} \\
55 \%_{2 y} \\
\text { OS } 27_{m}\end{array}$ \\
\hline $\begin{array}{l}\text { Romero et al. } \\
\text { [47] } \\
\text { Phase I-II }\end{array}$ & $25 / 34$ & $\begin{array}{l}1-3 \\
<7 \mathrm{~cm}\end{array}$ & $\begin{array}{l}\text { Mixed majority } \\
\mathrm{CRC}_{14}\end{array}$ & 12.9 & $\begin{array}{l}30-37.5 \text { Gy } \\
(3 \mathrm{fx})\end{array}$ & $\begin{array}{l}2 \% \text { Acute } \geq \mathrm{G} 3 \\
1 \% \text { Late } \mathrm{G} 3\end{array}$ & $\begin{array}{l}100 \%_{1 y} \\
86 \%_{2 y}\end{array}$ & $\begin{array}{l}85 \%_{1 y} \\
62 \%_{2 y}\end{array}$ \\
\hline $\begin{array}{l}\text { Rusthoven et al. } \\
\text { [48] } \\
\text { Phase I-II }\end{array}$ & $47 / 63$ & $\begin{array}{l}1-3 \\
<6 \mathrm{~cm}\end{array}$ & $\begin{array}{l}\text { Mixed majority } \\
\mathrm{CRC}_{15}\end{array}$ & 16 & $\begin{array}{l}36-60 \text { Gy } \\
(3 \mathrm{fx}) \\
\text { BED } \\
79-180 \text { Gy }\end{array}$ & $<2 \%$ Late G3/4 & $\begin{array}{l}95 \%_{1 y} \\
92 \%_{2 y}\end{array}$ & $\begin{array}{l}30 \%_{2 y} \\
\text { OS } 20.5_{m}\end{array}$ \\
\hline $\begin{array}{l}\text { Chang et al. } \\
\text { [49] } \\
\text { Phase I/pool }\end{array}$ & $65 / 102$ & $1-4$ & $\mathrm{CRC}_{65}$ & 14 & $\begin{array}{l}46-52 \text { Gy } \\
(1-6 \mathrm{fx}) \\
\text { BED } \\
82-100 \mathrm{~Gy}\end{array}$ & $\begin{array}{l}\text { Acute G3/4 3\% } \\
2 \text { late G3 }\end{array}$ & $\begin{array}{l}90 \%_{1 y} \\
43 \%_{2 y}\end{array}$ & NR \\
\hline $\begin{array}{l}\text { Scorsetti et al. } \\
\text { [50] } \\
\text { Phase II }\end{array}$ & 42 & $\begin{array}{l}1-3 \\
\leq 6 \mathrm{~cm}\end{array}$ & $\begin{array}{l}\text { Mixed majority } \\
\mathrm{CRC}_{42}\end{array}$ & 24 & $\begin{array}{l}75 \mathrm{~Gy} \\
(3 \mathrm{fx}) \\
\text { BED } 263 \mathrm{~Gy}\end{array}$ & No $\geq$ G3 & $91 \%_{2 y}$ & $\begin{array}{l}65 \%_{2 \mathrm{y}} \\
\text { OS } 29.2_{\mathrm{ms}}\end{array}$ \\
\hline $\begin{array}{l}\text { Andratschke } \\
\text { et al. [51] } \\
\text { Retrospective }\end{array}$ & $74 / 91$ & $1-4$ & $\begin{array}{l}\text { Mixed majority } \\
\mathrm{CRC}_{37}\end{array}$ & 15 & $\begin{array}{l}15-62.5 \text { Gy } \\
(3-5 \mathrm{fx})\end{array}$ & $\begin{array}{l}\text { No acute G3/5 } \\
\text { No late G4/5 }\end{array}$ & $\begin{array}{l}74.7 \%_{1 \mathrm{y}} \\
48.3 \%_{2 \mathrm{y}} \\
48.3 \%_{3 \mathrm{y}}\end{array}$ & $\begin{array}{l}77 \%_{1 y} \\
30 \%_{2 y} \\
27 \%_{3 y} \\
\text { OS } 27_{m}\end{array}$ \\
\hline $\begin{array}{l}\text { Goodman et al. } \\
\text { [52] } \\
\text { Retrospective }\end{array}$ & $81 / 106$ & $\begin{array}{l}1-3 \\
\leq 6 \mathrm{~cm}\end{array}$ & $\begin{array}{l}\text { Mixed majority } \\
\text { CRC }_{67 \%}\end{array}$ & 33 & $\begin{array}{l}54 \text { Gy } \\
(3-5 \text { fx }) \\
\text { BED 112- } \\
151 \text { Gy }\end{array}$ & $4.9 \% \mathrm{G} 3$ & $\begin{array}{l}96 \%_{1 y} \\
91 \%_{4 y}\end{array}$ & $\begin{array}{l}69 \% 2 y \\
44 \% 3 y \\
28 \% 4 y \\
\text { OS } 33.6_{m}\end{array}$ \\
\hline $\begin{array}{l}\text { Rubio et al. [53] } \\
\text { Retrospective }\end{array}$ & $21 / 101$ & $\begin{array}{l}3-14 \\
<8 \mathrm{~cm}\end{array}$ & $\begin{array}{l}\text { Mixed majority } \\
\mathrm{CRC}_{13}\end{array}$ & 23.2 & $\begin{array}{l}36-60 \text { Gy } \\
(3-5 \mathrm{fx})\end{array}$ & No $>$ G3 & $\begin{array}{l}94.4 \%_{1 y} \\
80.6 \%_{2 y} \\
65 \%_{4 y}\end{array}$ & $\begin{array}{l}57.6 \%_{5 y} \\
\text { OS } 62_{\mathrm{m}}\end{array}$ \\
\hline
\end{tabular}

$B E D$ biologically equivalent dose, $C R C$ colorectal cancer (subscript figures correspond to the number or proportion (\%) of patients exhibiting metastases, $f x$ fraction, $G$ grade, $G y$ gray, $L C$ local tumor control, $m$ month/s, $N R$ not reported, $O S$ overall survival, $y$ year/s 


\section{R0 resection is feasible, but FLR is inadequate in volume or quality}

Treatment is focused on improving the volume and function of FLR [54]. FLR of $25 \%$ is considered the minimum safe volume needed after hepatic resection in patients with a normal liver. However, in cases with sinusoidal obstruction syndrome (SOS), cholestasic, steatotic or cirrhotic liver, an FLR of $40 \%$ is required.

Percutaneous transhepatic portal vein embolization (PVE) is the gold standard to obtain adequate FLR hypertrophy. This procedure is performed by permanent occlusion of all right portal vein branches using different embolic agents. It is safe and effective and requires 3-5 weeks to achieve left lobe liver hypertrophy after embolization. According to a recent systematic review, the mean increase in the FRL volume was $37.9 \% \pm 0.1 \%(20.5-69.4 \%)$ [55]. Adequate hypertrophy (that allows liver resection) was obtained in 96.1\% of the procedures. Despite the good results of PVE, in approximately $15-20 \%$ of cases, planned liver resection is not performed. The main causes of these cancellations are extrahepatic tumor spread (8.1\%), local intrahepatic tumor progression or newly developed metastases in the FRL (6.1\%), and other causes (4.5\%).

\section{$\mathrm{R} 0$ resection is compromised as a result of a large tumor burden, but the volume, outflow, inflow and biliary drainage of FLR are adequate}

In such cases, patients require downstaging to obtain negative margin resection. These patients must undergo NCT and/or locoregional therapies, which target presurgical tumor shrinkage.

Transarterial radioembolization (TARE) with microspheres impregnated with yttrium- $90\left(\mathrm{Y}^{90}\right)$, a high-energy $\beta$ emitter with $2.5 \mathrm{~mm}$ tissue penetration, is a type of intraarterial brachytherapy targeted to hypervascular nodules in which neovascularization and the preference of arterial over portal perfusion determine a selective distribution of the device. This allows the safe administration of high doses of radiation to the tumor (tissue penetration range of 2,5 $\mathrm{mm}$ ). Standard TARE indication is palliative for patients with multifocal, unresectable liver-only or liver-dominant CRClm.

It is intended to make inoperable patients candidates for surgical resection or to simply facilitate the procedure by making lesions smaller, reducing their proximity to delicate vasculature, and preserving adjoining healthy liver tissue $[56,57]$. The REsect study, a blinded analysis of the patients included in the SIRFLOX trial, demonstrated that the combination of chemotherapy and TARE in patients with unresectable CRClm was associated with a statistically significant increase in the potentially curative resectability of the liver [58]. Currently, $\mathrm{Y}^{90}$ microspheres may also be a reasonable alternative in patients who are potential candidates for resection but display a small FLR [14]. Although PVE is the gold-standard modality for inducing hypertrophy of the FLR [59], Garlipp et al. [60] showed a lesser, but still pronounced, benefit of $\mathrm{Y}^{90}$ particles with regard to contralateral liver hypertrophy after TARE. Moreover, TARE minimizes the risk of tumor progression in the treated lobe, possibly making it a suitable modality for selected patients. An interval of 6 weeks between RE and follow-up imaging is considered appropriate, although the time to hypertrophy is heterogeneous, ranging in published studies from 44 days to 9 months.

\section{Sometimes both situations could be present}

Two decades ago, most of these patients were considered unresectable. However, thanks to the new strategies, development of a R0-resection and acceptable OS could be achieved. All these cases require downstaging of the tumor as well as increasing the volume and quality of the less affected lobe. Oncosurgical strategies for these patients include the following:

- Two-stage hepatectomy (TSH) TSH was described in 2000 by Adam et al. [61] as a strategy for patients with a poor prognosis as a result of widespread liver and bilobar tumors. First, hepatectomy aims to treat all metastases of the less-invaded hepatic lobe by resection or local ablation. If the volume of the FLR is inadequate, a contralateral portal vein branch percutaneous embolization or surgical ligature must be associated. The aim of the second hepatectomy is to perform a $\mathrm{R} 0$ resection. Usually, this stage consists of major hepatectomy of the high-involved lobe. Disease progression or recurrence and poor performance status after the first hepatectomy are the two most frequent reasons for not performing the second resection. This takes places in $28.1 \%$ of the cases [62]. Patients in whom the second stage is not performed have worse survival than those in which the strategy is completed. The 3-year OS rate was $45 \%$ when TSH was completed and 30\% when it was not. Likewise, the 5-year OS was $23 \%$ when the second stage could be performed and $0 \%$ when it could not.

Oncological outcomes of patients who require TSH are poorer than those who undergo $\mathrm{R} 0$ resection with a single hepatectomy in terms of 3-year OS (43.7\% vs 50.7\%) and 5 -year OS (21.4\% vs 32.4\%, $p=0.002)$ [63].

- ALPPS procedure Associating liver partition and portal vein ligation for stage hepatectomy (ALPPS) was described in 2012 as a new approach for patients with liver tumors initially deemed unresectable [64]. Since then, several authors have used this new strategy to increase the rate of resectable patients as an alternative 
to conventional approaches (i.e., TSH). However, in a subset of patients, ALPPS was performed in patients who might not have been eligible for any other operative treatment or even as a salvage procedure after insufficient future liver remnant hypertrophy following PVE [65]. The criteria for indicating the ALPPS procedure are not uniform and vary between working groups.

Whether TSH and ALPPS procedures have comparable results is an issue that needs to be addressed. Moris et al. [66] performed a recent meta-analysis comparing the results of two surgical strategies in patients with CRClm. The likelihood of patients proceeding to the second surgery varied greatly in TSH (range 63.3-100\%). However, all ALPPS patients underwent the second stage. No difference was noted with regard to the increase in FLR and postoperative FLR. However, the kinetic growth was faster for ALPPS (ALPPS vs TSH, mean difference: $19.07 \mathrm{ml} /$ day, $95 \%$ CI $8.12-30.02, p=0.0006)$. Therefore, the time to perform the second surgery was shorter for ALPPS than for TSH. In relation to postoperative results, ALPPS was associated with a higher incidence of major morbidity (relative risk 1.57, $95 \%$ confidence interval $[\mathrm{CI}]: 1.18-2.08, p=0.002)$, overall morbidity (relative risk $1.39,95 \% \mathrm{CI} 1.07-1.8, p=0.01$ ) and mortality (relative risk 1.84, 95\% CI 1.03-3.3, $p=0.04$ ). However, due to the learning curve, mortality decreases in centers with high volume ( $4 \%$ in centers with $\geq 8$ procedures vs $13 \%$ in centers with $<8$ procedures).

Long-term oncological results have been assessed only by a few authors. Most of them reported comparable OS. Only Adam et al. [67] described worse OS (median survival: 20 months for ALPPS vs 37 months for TSH, $p=0.006$ ) but similar disease-free survival. In addition, recurrence-free survival was similar in studies that specifically reported this outcome [66]. Taking into account the reported increased mortality rate and similar oncologic outcomes, an adequate selection of patients is necessary to optimize the ALPPS results.

\section{Role of systemic treatment}

In 2004, Adam et al. [68] published the rescue of $12.5 \%$ of patients with initially unresectable liver metastases (IULM) after treatment with chemotherapy, confirming previous data from Bismuth. Despite a high recurrence rate, the 5-year survival rate was $33 \%$. Oxaliplatin-based chemotherapy was administered in $70 \%$ of cases [68]. The survival benefit obtained, which exceeds that of patients treated exclusively with chemotherapy, introduced the concept of conversion chemotherapy.

However, new questions arise, such as the definition of irresectability, the optimal time for re-evaluation and maximum response, the method of radiological evaluation, the optimal scheme of chemotherapy or the survival benefit of this strategy when faced with new targeted therapies.

Response to treatment should be closely monitored every 2 months to perform the resection as soon as the metastases become resectable, avoiding further progression or liver toxicity [69]. Since anti-angiogenic treatments have little influence on tumor size, criteria based on the morphological modifications of the lesions were described. These criteria were correlated with pathological response and OS [70].

Regarding the optimal treatment regimen, since resection rates are related to response rates (RRs) to treatment, we have to look for schemes with high RRs or with an important decrease in time to response. Folprecht et al. [55] showed a strong correlation between RRs and resection rates in patients with exclusively liver disease. This observation should be viewed with caution since the treatment schemes used in the analyzed studies were different.

Several studies showed R0-resection rates of 11-33\% after doublets of chemotherapy with either irinotecan or oxaliplatin plus 5-fluorouracil. Subsequently, the combination of oxaliplatin, irinotecan, leucovorin, and 5-fluorouracil (FOLFOXIRI) demonstrated benefits in RR, R0-resection rate, PFS and OS versus the combination of 5-fluorouracil, leucovorin, and irinotecan (FOLFIRI) in a randomized study [71].

The current trend is to combine targeted therapies with chemotherapy to obtain the highest RR. Addition of antiEGFR to chemotherapy obtained a significant benefit in RRs and higher R0-resections rates in native RAS patients [72]. In the CELIM trial, the addition of cetuximab to FOLFOX-4 obtained a significant benefit in RRs and higher R0-resection rates in native KRAS patients [73]. Other studies show similar data [72]. The combination of cetuximab/panitumumab with a triplet of chemotherapy has also been studied. In the POCHE study, cetuximab + chronoIFLO achieved a R0 resection rate of 60\% in IULM patients [74]. In the PLANET trial, a randomized, open-label trial conducted in 77 untreated patients with (WT)-KRAS mCRC and multiple or unresectable liver-limited disease, patients received panitumumab-FOLFOX4 or panitumumab-FOLFIRI and the ORR was $74 \%$ with panitumumab-FOLFOX4 and $45 \%$ and $59 \%$ underwent surgical resection [75].

Regarding bevacizumab, a multicenter study showed a high RR in patients with IULM when combined with CAPOX, transforming $40 \%$ of cases into resectable [76]. In the TRIBE trial, FOLFOXIRI/bevacizumab had a benefit in PFS and RR compared to FOLFIRI/bevacizumab, without differences in R0-resection rates [77]. A subsequent analysis also showed survival benefit. In the OLIVIA study, bevacizumab/FOLFOXIRI was associated with a higher RR, resection rate and increase in PFS compared with bevacizumab/ mFOLFOX6 (a dose modification of FOLFOX) [78]. 
Based on these findings, we can consider the combination of a doublet of chemotherapy combined with antibodies against EGFR in patients with RAS wild-type mCRC or the combination of FOLFOXIRI \pm bevacizumab, the standard treatment options in this situation.

\section{Unresectable liver metastases}

These patients could be defined as those with multiple and bilobar disease who avoid obtaining a R0 resection by maintaining an adequate FLR [20-25\% of total liver volume as future liver remnant (FLR) with adequate inflow, outflow and biliary drainage]. Currently, there are no criteria that allow us to distinguish between those patients for whom purely palliative treatment and those for whom potentially curative treatment is appropriate. Due to the increasing efficacy of systemic drugs and agents, patients with CLM only must be considered definitively unresectable after receiving 2-4 months of optimal treatment, when the maximal tumor shrinkage is deemed to have occurred in most cases. Therefore, the opportunity for resection is not missed in patients who a priori have a low chance of further resection.

\section{Role of systemic therapy}

These patients could be defined as those with multiple and bilobar disease, which prevents obtaining a R0 resection by maintaining adequate FLR. Due to the increasing efficacy of systemic therapy, patients with CRClm only must be considered definitively unresectable after receiving 2-4 months of optimal treatment.

The choice of a systemic treatment strategy is based on patient-related factors, the mutational profile of the tumor, and the differing toxicity profiles of the constituent drugs [14].

The chemotherapy options for the treatment of patients with metastatic CRC are typically a cytotoxic doublet such as FOLFOX, CAPOX or FOLFIRI or, in selected patients, the triplet FOLFOXIRI or fluoropyrimidine monotherapy in unfit patients.

All patients considered for systemic therapy should be stratified according to RAS and BRAF mutations [79].

RAS wild-type The combination of chemotherapy plus anti-EGFR therapy has shown benefit over exclusive chemotherapy. Bevacizumab is an anti-angiogenic drug with proven benefits in combination with chemotherapy $[80,81]$. Two phase III studies have compared the combination of chemotherapy and anti-EGFR vs chemotherapy and bevacizumab with discordant results. The FIRE- 3 trial compared FOLFIRI plus cetuximab to FOLFIRI plus bevacizumab in a first-line, KRAS exon 2 wild type [82]. This trial did not meet its primary endpoint of the investigator-read objective response rate. PFS was nearly identical between the arms, but a statistically significant improvement in OS was reported in the cetuximab arm (28.7 vs. 25.0 months). Updated analysis with all RAS mutations considered showed similar results. In the CALGB/SWOG 80,405 trial [83], comparing FOLFOX/FOLFIRI with cetuximab or bevacizumab, the primary endpoint of OS was equivalent between the arms (29.0 vs 29,9 months). Based on these data, the addition of anti-EGFR therapy or the addition of bevacizumab to chemotherapy are equivalent choices in the firstline, RAS wild-type, metastatic setting.

RAS mutant Bevacizumab has demonstrated its effectiveness independent of the state of RAS; therefore, the treatment of choice in these patients is the combination of chemotherapy plus bevacizumab in those who can tolerate an intensive treatment [84].

BRAF mutant Approximately 5-9\% of colorectal cancers are characterized by a specific mutation in the BRAF gene (V600E). The evidence increasingly suggests that BRAF V600E mutation is associated with poor response to panitumumab or cetuximab, as single agents or in combination with cytotoxic chemotherapy [85]. Another option is the possibility of adding bevacizumab to FOLFOXIRI. The results of the phase III TRIBE trial showed that in the patients with BRAF mutation treated with FOLFOXIRI plus bevacizumab, the median OS was 19 months, the median PFS was 7.5 months, and the best response was $56 \%$. Based on these data, FOLFOXIRI plus bevacizumab is recommended in patients with BRAF mutant [77].

The role of primary tumor sidedness The results of a retrospective pooled analysis of six trials (CRYSTAL, FIRE3, CALGB 80,405, PRIME and PEAK in first line, and $20,050,181$ in second line) on the prognostic and predictive value of primary tumor location (left- versus right-sided) for the treatment of patients with RAS wt mCRC with chemotherapy and EGFR antibody therapy have been published [86]. The individual trial data for the six trials showed that patients with left-sided tumors receiving chemotherapy plus EGFR antibody therapy had superior treatment outcomes in terms of overall survival, PFS and response rate compared to patients with right-sided tumors. A significant benefit $(p<0.001)$ of chemotherapy plus EGFR therapy was observed in patients with left-sided tumors for overall survival and PFS compared with no benefit in patients with right-sided tumors. Patients in the FIRE-3 and CALGB 80,405 first-line trials, with left-sided RAS wt, receiving chemotherapy plus EGFR antibody therapy, had significantly better treatment outcomes in terms of overall survival, PFS and response rate than those receiving chemotherapy plus Bev. Limited benefit was observed from EGFR antibody therapy in patients with right-sided tumors. Furthermore, individual patient data for patients with right-sided tumors from the FIRE-3 trial suggested that patients with 
right-sided RAS wt tumors might benefit from chemotherapy plus bevacizumab compared with cetuximab in terms of overall survival but not ORR.

\section{Locoregional therapies}

Locoregional treatment also plays a role in non-resectable patients $[14,36]$. Recently, the CLOCC trial has marked a shift in the paradigm of percutaneous ablation in metastatic CRC. The goal is not necessarily to cure the patient. According to this study, radiofrequency or microwave ablation is not limited to patients with resectable tumors and may not be limited by the size of the metastatic nodule. After 7,8 years of follow-up, in patients with advanced disease who obtained a reduction of the tumoral load by applying additional aggressive treatment consisting of local ablation plus systemic treatment, a beneficial effect was demonstrated clinically and was associated with a statistically significant improvement in overall survival [87]

Chemoembolization is also indicated in some non-resectable patients. Use of drug eluting beads, TACE with irinotecan (DEBIRI), is indicated as a third-line treatment when systemic chemotherapy has failed [88, 89]. Selective intraarterial administration of irinotecan inside tumoral arteries, while the embolization limits drug washout, permits a higher and prolonged intratumoral dose of irinotecan and up to $70-75 \%$ lower plasma levels [90]. Current evidence for DEBIRI is mostly limited to the salvage setting. Two randomized controlled trials demonstrated an improved objective response rate (ORR) compared with FOLFOX and FOLFIRI [91, 92]. DEBIRI could provide an opportunity for some patients who need downstaging prior to surgery [93].

There is clinical evidence that the use of TARE is safe and well tolerated. TARE is indicated in third-line liverdominant disease after chemotherapy or in combination with chemotherapy $[94,95]$. The results obtained in different studies are homogenous with regards to ORR, which ranged between 24 and $41 \%$, and OS, which ranged between 8 and 13 months [94-98]. The level of evidence of the clinical data obtained so far from more than 1,500 patients has led to the inclusion of $90 \mathrm{Y}$ microspheres in the 2016 ESMO Clinical Guidelines (recommendation 16) [14]. Regarding radioembolization within the therapeutic algorithm of metastatic CRC, it is not entirely clear. Kennedy et al. [97] evaluated the experience of 11 US centers and found median survival following radioembolization as a secondline, third-line, or fourth-plus line therapy of 13.0 (range, 10.5-14.6), 9.0 (range, 7.8-11.0), and 8.1 (range, 6.4-9.3) months, respectively. There are phase III trials, such as the TS-102 EPOCH, currently underway; in these studies, radioembolization associated with chemotherapy is included in the second line, which aims to clarify the ideal place for this therapy within the therapeutic algorithm.
Recent trials have been carried out to demonstrate the utility of TARE in first-line treatment associated with chemotherapy regimens. The results of phase III randomized controlled trials have recently been published. The combined study results represent the largest randomized analysis performed in the field of interventional oncology to address the question of whether improved local control of colorectal liver metastases impacts overall survival. Chemotherapynaive patients were included and assigned to either oxaliplatin-based chemotherapy (FOLFOX: leucovorin, fluorouracil, and oxaliplatin) or FOLFOX plus single treatment TARE concurrent with cycle 1 or 2 of chemotherapy $[95,99]$.

Although PFS, as the primary endpoint, was not met, a prolonged liver PFS was demonstrated for the study arm (20.5 months for the FOLFOX/90Y arm vs 12,6 months for the chemotherapy only arm; hazard ratio 0,$69 ; 95 \% \mathrm{CI}$, $0,55-0,90 ; p=0.002)$. This difference was even greater in patients without extrahepatic disease (12.4 vs 21.1 months) $[99,100]$.

A post hoc analysis of data from these trials indicates that adding TARE to standard first-line mFOLFOX6 chemotherapy in patients with right-sided primary tumors led to a statistically significant and clinically meaningful 4.9-month median overall survival benefit (hazard ratio $0.64 ; 95 \% \mathrm{CI}$, $0.46-0.89 ; p=0.007)$. This translates into a $36 \%$ reduction in the risk of death at any given time compared to patients who received chemotherapy alone [101]. To further define the role of TARE in metastatic colorectal cancer, careful patient selection, including the side of the primary tumor, and studies investigating the role of TARE as consolidation therapy after chemotherapy are needed.

In conclusion, locoregional therapies also play a role in unresectable CRClm. Ablation for the debulking of liver metastasis has demonstrated an increase in OS. TACE with irinotecan has demonstrated an RCT benefit in terms of OS, PFS and QoL. TARE is safe and well tolerated, and, according to 2016 ESMO Clinical Guidelines, is indicated as a third-line treatment for liver-dominant disease.

\section{Conclusions}

Liver metastatic disease from colorectal cancer is a complex clinical situation that requires evaluation by a multidisciplinary team. The first step must be to clearly define if we are dealing with a resectable disease, if the tumor may be resectable after systemic treatment or if we are facing a non-resectable metastasis, and primary tumor management must be considered in cases of synchronous metastases. In addition to this evaluation, performance status of the patient must be assessed. Figures $1 \mathrm{a}$ and $\mathrm{b}$ show the proposed treatment algorithm.

The following aspects should be kept in mind: 
- Surgical resection is the only curative treatment and the "gold standard" when resectable liver metastases are present in a fit patient

- In this setting, neoadjuvant chemotherapy might provide benefit in high-risk patients

- Neoadjuvant chemotherapy may initially turn unresectable liver metastases into resectable liver metastases with good long-term results. Percutaneous transhepatic portal vein embolization, two-stage hepatectomy and ALPPS are useful surgical techniques to achieve R0 resections.

- Systemic chemotherapy is the standard of care for patients with non-resectable disease. The choice of a systemic treatment strategy is based on patient-related factors, the mutational profile of the tumor, and the differing toxicity profiles of the constituent drugs.

- Ablative treatments (RF, MW ablation, cryoablation, and SBRT) are good alternatives for patients who have technically resectable disease, but the metastases are inoperable due to poor clinical conditions or comorbidities.

- TARE, TACE, and ablative treatments may play a role in the palliative setting for patients with CRClm.

Acknowledgements The authors would like to thank Fernando RicoVillademoros (COCIENTE SL, Madrid, Spain) for editorial assistance in the preparation of this manuscript. His participation has been funded by the participating scientific societies.

Funding This consensus was equally funded by the Spanish Society of Medical Oncology, the Spanish Association of Surgeons, the Spanish Society of Radiation Oncology, the Spanish Society of Vascular and Interventional Radiology, and the Spanish Society of Nuclear Medicine and Molecular Imaging.

\section{Compliance with ethical standards}

Conflict of interest R. Vera has received consultant fees from Roche, Amgen, Merck Sharp \& Dohme, Sanofi, and Bristol Myer Squibb; has received advisory honorarium from Roche, Amgen, Merck Sharp \& Dohme, Sanofi. J. Urbano declares no conflict of interest regarding this manuscript. E. González-Flores has received advisory honorarium from Roche, Amgen, Merck Sharp \& Dohme, Sanofi. J. Orcajo Rincón declares no conflict of interest regarding this manuscript. M. Valero Camps declares no conflict of interest regarding this manuscript. J.J. Ciampi-Dopazo declares no conflict of interest regarding this manuscript. V. Morillo Macías declares no conflict of interest regarding this manuscript. C. Rubio declares no conflict of interest regarding this manuscript. M. A. Gomez Bravo declares no conflict of interest regarding this manuscript. G. Suarez-Artacho declares no conflict of interest regarding this manuscript.

Research involving human participants and/or animals/Informed consent/Ethics approval The manuscript does not contain clinical studies or patient data.
Open Access This article is distributed under the terms of the Creative Commons Attribution 4.0 International License (http://creativeco mmons.org/licenses/by/4.0/), which permits unrestricted use, distribution, and reproduction in any medium, provided you give appropriate credit to the original author(s) and the source, provide a link to the Creative Commons license, and indicate if changes were made.

\section{References}

1. Ferlay J, Steliarova-Foucher E, Lortet-Tieulent J, Rosso S, Coebergh JW, Comber H, Forman D, Bray F. Cancer incidence and mortality patterns in Europe: estimates for 40 countries in 2012. Eur J Cancer. 2013;49:1374-403.

2. Ferlay J, Soerjomataram I, Dikshit R, Eser S, Mathers C, Rebelo M, Parkin DM, Forman D, Bray F. Cancer incidence and mortality worldwide: sources, methods and major patterns in GLOBOCAN 2012. Int J Cancer. 2015;136:E359-E386386.

3. Leporrier J, Maurel J, Chiche L, Bara S, Segol P, Launoy G. A population-based study of the incidence, management and prognosis of hepatic metastases from colorectal cancer. Br J Surg. 2006;93:465-74.

4. Bekaii-Saab T, Wu C. Seeing the forest through the trees: a systematic review of the safety and efficacy of combination chemotherapies used in the treatment of metastatic colorectal cancer. Crit Rev Oncol Hematol. 2014;91:9-34.

5. Hellman S, Weichselbaum RR. Oligometastases. J Clin Oncol. 1995;13:8-10.

6. Kanas GP, Taylor A, Primrose JN, Langeberg WJ, Kelsh MA, Mowat FS, Alexander DD, Choti MA, Poston G. Survival after liver resection in metastatic colorectal cancer: review and metaanalysis of prognostic factors. Clin Epidemiol. 2012;4:283-301.

7. Reiter MJ, Hannemann NP, Schwope RB, Lisanti CJ, Learn PA. Role of imaging for patients with colorectal hepatic metastases: what the radiologist needs to know. Abdom Imaging. 2015;40:3029-42.

8. Adam R, De Gramont A, Figueras J, Kokudo N, Kunstlinger F, Loyer E, Poston G, Rougier P, Rubbia-Brandt L, Sobrero A, Teh C, Tejpar S, Van Cutsem E, Vauthey JN, Pahlman L. Managing synchronous liver metastases from colorectal cancer: a multidisciplinary international consensus. Cancer Treat Rev. 2015;41:729-41.

9. Scharitzer M, Ba-Ssalamah A, Ringl H, Kolblinger C, Grunberger T, Weber M, Schima W. Preoperative evaluation of colorectal liver metastases: comparison between gadoxetic acid-enhanced 3.0-T MRI and contrast-enhanced MDCT with histopathological correlation. Eur Radiol. 2013;23:2187-96.

10. Ryu SW, Bok GH, Jang JY, Jeong SW, Ham NS, Kim JH, Park EJ, Kim JN, Lee WC, Shim KY, Lee SH, Kim SG, Cha SW, Kim YS, Cho YD, Kim HS, Kim BS. Clinically useful diagnostic tool of contrast enhanced ultrasonography for focal liver masses: comparison to computed tomography and magnetic resonance imaging. Gut Liver. 2014;8:292-7.

11. Moulton CA, Gu CS, Law CH, Tandan VR, Hart R, Quan D, Smith RJF, Jalink DW, Husien M, Serrano PE, Hendler AL, Haider MA, Ruo L, Gulenchyn KY, Finch T, Julian JA, Levine $\mathrm{MN}$, Gallinger S. Effect of PET before liver resection on surgical management for colorectal adenocarcinoma metastases: a randomized clinical trial. JAMA. 2014;311:1863-9.

12. Maffione AM, Lopci E, Bluemel C, Giammarile F, Herrmann K, Rubello D. Diagnostic accuracy and impact on management of (18)F-FDG PET and PET/CT in colorectal liver metastasis: a meta-analysis and systematic review. Eur J Nucl Med Mol Imaging. $2015 ; 42: 152-63$. 
13. Joyce DL, Wahl RL, Patel PV, Schulick RD, Gearhart SL, Choti MA. Preoperative positron emission tomography to evaluate potentially resectable hepatic colorectal metastases. Arch Surg. 2006;141:1220-6; (discussion 7).

14. Van Cutsem E, Cervantes A, Adam R, Sobrero A, Van Krieken JH, Aderka D, Aguilar EA, Bardelli A, Benson A, Bodoky G, Ciardiello F, D'Hoore A, Diaz-Rubio E, Douillard JY, Ducreux M, Falcone A, Grothey A, Gruenberger T, Haustermans K, Heinemann V, Hoff P, Kohne CH, Labianca R, Laurent-Puig P, Ma B, Maughan T, Muro K, Normanno N, Osterlund P, Oyen WJ, Papamichael D, Pentheroudakis G, Pfeiffer P, Price TJ, Punt C, Ricke J, Roth A, Salazar R, Scheithauer W, Schmoll HJ, Tabernero J, Taieb J, Tejpar S, Wasan H, Yoshino T, Zaanan A, Arnold D. ESMO consensus guidelines for the management of patients with metastatic colorectal cancer. Ann Oncol. 2016;27:1386-422.

15. Hendlisz A, Golfinopoulos V, Garcia C, Covas A, Emonts P, Ameye L, Paesmans M, Deleporte A, Machiels G, Toussaint E, Vanderlinden B, Awada A, Piccart M, Flamen P. Serial FDGPET/CT for early outcome prediction in patients with metastatic colorectal cancer undergoing chemotherapy. Ann Oncol. 2012;23:1687-93.

16. Lu YY, Chen JH, Chien CR, Chen WT, Tsai SC, Lin WY, Kao $\mathrm{CH}$. Use of FDG-PET or PET/CT to detect recurrent colorectal cancer in patients with elevated CEA: a systematic review and meta-analysis. Int J Colorectal Dis. 2013;28:1039-47.

17. Pawlik TM, Choti MA. Surgical therapy for colorectal metastases to the liver. J Gastrointest Surg. 2007;11:1057-77.

18. Zhu D, Zhong Y, Wei Y, Ye L, Lin Q, Ren L, Ye Q, Liu T, Xu J, Qin X. Effect of neoadjuvant chemotherapy in patients with resectable colorectal liver metastases. PLoS ONE. 2014;9:e86543.

19. Vigano L, Capussotti L, Lapointe R, Barroso E, Hubert C, Giuliante F, Ijzermans JN, Mirza DF, Elias D, Adam R. Early recurrence after liver resection for colorectal metastases: risk factors, prognosis, and treatment. A LiverMetSurvey-based study of 6,025 patients. Ann Surg Oncol. 2014;21:1276-86.

20. Fong Y, Fortner J, Sun RL, Brennan MF, Blumgart LH. Clinical score for predicting recurrence after hepatic resection for metastatic colorectal cancer: analysis of 1001 consecutive cases. Ann Surg. 1999;230(3):309-18.

21. Margonis GA, Sasaki K, Gholami S, Kim Y, Andreatos N, Rezaee N, Deshwar A, Buettner S, Allen PJ, Kingham TP, Pawlik TM, He J, Cameron JL, Jarnagin WR, Wolfgang CL, D'Angelica MI, Weiss MJ. Genetic And Morphological Evaluation (GAME) score for patients with colorectal liver metastases. Br J Surg. 2018;105(9):1210-20. https://doi.org/10.1002/bjs.10838.

22. Reddy SK, Barbas AS, Turley RS, Steel JL, Tsung A, Marsh JW, Geller DA, Clary BM. A standard definition of major hepatectomy: resection of four or more liver segments. HPB (Oxford). 2011;13:494-502.

23. Makowiec F, Bronsert P, Klock A, Hopt UT, Neeff HP. Prognostic influence of hepatic margin after resection of colorectal liver metastasis: role of modern preoperative chemotherapy. Int J Colorectal Dis. 2018;33:71-8.

24. Andreou A, Aloia TA, Brouquet A, Dickson PV, Zimmitti G, Maru DM, Kopetz S, Loyer EM, Curley SA, Abdalla EK, Vauthey JN. Margin status remains an important determinant of survival after surgical resection of colorectal liver metastases in the era of modern chemotherapy. Ann Surg. 2013;257:1079-88.

25. Gold JS, Are C, Kornprat P, Jarnagin WR, Gonen M, Fong Y, DeMatteo RP, Blumgart LH, D'Angelica M. Increased use of parenchymal-sparing surgery for bilateral liver metastases from colorectal cancer is associated with improved mortality without change in oncologic outcome: trends in treatment over time in 440 patients. Ann Surg. 2008;247:109-17.
26. Memeo R, De Blasi V, Adam R, Goéré D, Azoulay D, Ayav A, Gregoire E, Kianmanesh R, Navarro F, Sa Cunha A, Pessaux P, French Colorectal Liver Metastases Working Group, Association Française de Chirurgie (AFC). Parenchymal-sparing hepatectomies (PSH) for bilobar colorectal liver metastases are associated with a lower morbidity and similar oncological results: a propensity score matching analysis. HPB (Oxford). 2016;18:781-90.

27. Nordlinger B, Sorbye H, Glimelius B, Poston GJ, Schlag PM, Rougier P, Bechstein WO, Primrose JN, Walpole ET, FinchJones M, Jaeck D, Mirza D, Parks RW, Collette L, Praet M, Bethe U, Van Cutsem E, Scheithauer W, Gruenberger T. Perioperative chemotherapy with FOLFOX4 and surgery versus surgery alone for resectable liver metastases from colorectal cancer (EORTC intergroup trial 40983): a randomised controlled trial. Lancet. 2008;371:1007-166.

28. Adam R, Pascal G, Castaing D, Azoulay D, Delvart V, Paule B, Levi F, Bismuth H. Tumor progression while on chemotherapy: a contraindication to liver resection for multiple colorectal metastases? Ann Surg. 2004;240:1052-61; (discussion 61-4).

29. Ciliberto D, Prati U, Roveda L, Barbieri V, Staropoli N, Abbruzzese A, Caraglia M, Di Maio M, Flotta D, Tassone P, Tagliaferri P. Role of systemic chemotherapy in the management of resected or resectable colorectal liver metastases: a systematic review and meta-analysis of randomized controlled trials. Oncol Rep. 2012;27:1849-56.

30. Araujo RL, Gonen M, Herman P. Chemotherapy for patients with colorectal liver metastases who underwent curative resection improves long-term outcomes: systematic review and meta-analysis. Ann Surg Oncol. 2015;22:3070-8.

31. Nordlinger B, Sorbye H, Glimelius B, Poston GJ, Schlag PM, Rougier P, Bechstein WO, Primrose JN, Walpole ET, FinchJones M, Jaeck D, Mirza D, Parks RW, Mauer M, Tanis E, Van Cutsem E, Scheithauer W, Gruenberger T. Perioperative FOLFOX 4 chemotherapy and surgery versus surgery alone for resectable liver metastases from colorectal cancer (EORTC 40983): long-term results of a randomised, controlled, phase 3 trial. Lancet Oncol. 2013;14:1208-15.

32. Primrose J, Falk S, Finch-Jones M, Valle J, O'Reilly D, Siriwardena A, Hornbuckle J, Peterson M, Rees M, Iveson T, Hickish T, Butler R, Stanton L, Dixon E, Little L, Bowers M, Pugh S, Garden OJ, Cunningham D, Maughan T, Bridgewater J. Systemic chemotherapy with or without cetuximab in patients with resectable colorectal liver metastasis: the new EPOC randomised controlled trial. Lancet Oncol. 2014;15:601-11.

33. Cirocchi R, Trastulli S, Boselli C, Montedori A, Cavaliere D, Parisi A, Noya G, Abraha I. Radiofrequency ablation in the treatment of liver metastases from colorectal cancer. Cochrane Database Syst Rev. 2012:CD006317. https://doi. org/10.1002/14651858.CD006317.pub3

34. Crocetti L, De Baere T, Lencioni R. Quality improvement guidelines for radiofrequency ablation of liver tumours. Cardiovasc Interv Radiol. 2010;33:11-7.

35. Gazelle GS, Goldberg SN, Solbiati L, Livraghi T. Tumor ablation with radio-frequency energy. Radiology. 2000;217:633-46.

36. De Baere T, Tselikas L, Yevich S, Boige V, Deschamps F, Ducreux M, Goere D, Nguyen F, Malka D. The role of imageguided therapy in the management of colorectal cancer metastatic disease. Eur J Cancer. 2017;75:231-42.

37. Puijk RS, Ruarus AH, Vroomen L, Van Tilborg A, Scheffer HJ, Nielsen K, De Jong MC, De Vries JJJ, Zonderhuis BM, Eker HH, Kazemier G, Verheul H, Van der Meijs BB, Van Dam L, Sorgedrager N, Coupe VMH, Van den Tol PMP, Meijerink MR. Colorectal liver metastases: surgery versus thermal ablation (COLLISION) - a phase III single-blind prospective randomized controlled trial. BMC Cancer. 2018;18:821. 
38. Wild AT, Yamada Y. Treatment options in oligometastatic disease: stereotactic body radiation therapy - focus on colorectal cancer. Visc Med. 2017;33:54-61.

39. Shady W, Petre EN, Gonen M, Erinjeri JP, Brown KT, Covey AM, Alago W, Durack JC, Maybody M, Brody LA, Siegelbaum RH, D'Angelica MI, Jarnagin WR, Solomon SB, Kemeny NE, Sofocleous CT. Percutaneous radiofrequency ablation of colorectal cancer liver metastases: factors affecting outcomes-A 10-year experience at a single center. Radiology. 2016;278:601-11.

40. Shady W, Petre EN, Do KG, Gonen M, Yarmohammadi H, Brown KT, Kemeny NE, D’Angelica M, Kingham PT, Solomon SB, Sofocleous CT. Percutaneous microwave versus radiofrequency ablation of colorectal liver metastases: ablation with clear margins (A0) provides the best local tumor control. J Vasc Interv Radiol. 2018;29(268-75):e1.

41. Gillams A, Goldberg N, Ahmed M, Bale R, Breen D, Callstrom M, Chen MH, Choi BI, De Baere T, Dupuy D, Gangi A, Gervais D, Helmberger T, Jung EM, Lee F, Lencioni R, Liang P, Livraghi T, Lu D, Meloni F, Pereira P, Piscaglia F, Rhim H, Salem R, Sofocleous C, Solomon SB, Soulen M, Tanaka M, Vogl T, Wood B, Solbiati L. Thermal ablation of colorectal liver metastases: a position paper by an international panel of ablation experts, the interventional oncology sans frontieres meeting 2013. Eur Radiol. 2015;25:3438-54.

42. Calandri M, Yamashita S, Gazzera C, Fonio P, Veltri A, Bustreo S, Sheth RA, Yevich SM, Vauthey JN, Odisio BC. Ablation of colorectal liver metastasis: interaction of ablation margins and RAS mutation profiling on local tumour progression-free survival. Eur Radiol. 2018;28:2727-34.

43. Distelmaier M, Barabasch A, Heil P, Kraemer NA, Isfort P, Keil S, Kuhl CK, Bruners P. Midterm safety and efficacy of irreversible electroporation of malignant liver tumors located close to major portal or hepatic veins. Radiology. 2017;285:1023-31.

44. Scorsetti M, Clerici E, Comito T. Stereotactic body radiation therapy for liver metastases. J Gastrointest Oncol. 2014;5:190-7.

45. Blomgren H, Lax I, Naslund I, Svanstrom R. Stereotactic high dose fraction radiation therapy of extracranial tumors using an accelerator. Clinical experience of the first thirty-one patients. Acta Oncol. 1995;34:861-70.

46. Herfarth KK, Debus J, Wannenmacher M. Stereotactic radiation therapy of liver metastases: update of the initial phase-I/II trial. Front Radiat Ther Oncol. 2004;38:100-5.

47. Romero AM, Wunderink W, Hussain SM, De Pooter JA, Heijmen BJ, Nowak PC, Nuyttens JJ, Brandwijk RP, Verhoef C, Ijzermans JN, Levendag PC. Stereotactic body radiation therapy for primary and metastatic liver tumors: a single institution phase $\mathrm{i}-\mathrm{ii}$ study. Acta Oncol. 2006;45:831-7.

48. Rusthoven KE, Kavanagh BD, Cardenes H, Stieber VW, Burri SH, Feigenberg SJ, Chidel MA, Pugh TJ, Franklin W, Kane M, Gaspar LE, Schefter TE. Multi-institutional phase I/II trial of stereotactic body radiation therapy for liver metastases. J Clin Oncol. 2009;27:1572-8.

49. Chang DT, Swaminath A, Kozak M, Weintraub J, Koong AC, Kim J, Dinniwell R, Brierley J, Kavanagh BD, Dawson LA, Schefter TE. Stereotactic body radiotherapy for colorectal liver metastases: a pooled analysis. Cancer. 2011;117:4060-9.

50. Scorsetti M, Comito T, Tozzi A, Navarria P, Fogliata A, Clerici E, Mancosu P, Reggiori G, Rimassa L, Torzilli G, Tomatis S, Santoro A, Cozzi L. Final results of a phase II trial for stereotactic body radiation therapy for patients with inoperable liver metastases from colorectal cancer. J Cancer Res Clin Oncol. 2015;141:543-53.
51. Andratschke NH, Nieder C, Heppt F, Molls M, Zimmermann F. Stereotactic radiation therapy for liver metastases: factors affecting local control and survival. Radiat Oncol. 2015;10:69.

52. Goodman BD, Mannina EM, Althouse SK, Maluccio MA, Cardenes HR. Long-term safety and efficacy of stereotactic body radiation therapy for hepatic oligometastases. Pract Radiat Oncol. 2016;6:86-95.

53. Rubio C, Hernando-Requejo O, Zucca Aparicio D, Krauel MA, Gonzalez ML, Pérez JM, Saugar ES, Letón PF. Image guided SBRT for multiple liver metastases with ExacTrac(®) adaptive gating. Rep Pract Oncol Radiother. 2017;22:150-7.

54. Qadan M, D’Angelica MI. Complex surgical strategies to improve resectability in borderline-resectable disease. Curr Colorectal Cancer Rep. 2015;11:369-77.

55. Van Lienden KP, Van den Esschert JW, De Graaf W, Bipat S, Lameris JS, Van Gulik TM, Van Delden OM. Portal vein embolization before liver resection: a systematic review. Cardiovasc Interv Radiol. 2013;36:25-34.

56. Wasan H, Kennedy A, Coldwell D, Sangro B, Salem R. Integrating radioembolization with chemotherapy in the treatment paradigm for unresectable colorectal liver metastases. Am J Clin Oncol. 2012;35:293-301.

57. Folprecht G, Grothey A, Alberts S, Raab HR, Kohne CH. Neoadjuvant treatment of unresectable colorectal liver metastases: correlation between tumour response and resection rates. Ann Oncol. 2005;16:1311-9.

58. Garlipp B, Gibbs P, Hazel G, Jeyarajah R, Martin RSG, Bruns CJ, Lang H, Manas D, Ettorre GM, Pardo F, Donckier V, Benckert C, Van Gulik TM, Goere D, Schön M, Pratschke J, Bechstein W, Cuesta AM, Adeyemi S, Seidensticker M. REsect: blinded assessment of amenability to potentially curative treatment of previously unresectable colorectal cancer liver metastases (CRC LM) after chemotherapy \pm radioembolization (SIRT) in the randomized SIRFLOX trial. J Clin Oncol. 2017;35:3532.

59. Teo JY, Allen JC, Ng DC, Choo SP, Tai DW, Chang JP, Cheah FK, Chow PK, Goh BK. A systematic review of contralateral liver lobe hypertrophy after unilobar selective internal radiation therapy with Y90. HPB (Oxford). 2016;18:7-12.

60. Garlipp B, De Baere T, Damm R, Irmscher R, Van Buskirk M, Stubs P, Deschamps F, Meyer F, Seidensticker R, Mohnike K, Pech M, Amthauer H, Lippert H, Ricke J, Seidensticker M. Leftliver hypertrophy after therapeutic right-liver radioembolization is substantial but less than after portal vein embolization. Hepatology. 2014;59:1864-73.

61. Adam R, Laurent A, Azoulay D, Castaing D, Bismuth H. Twostage hepatectomy: a planned strategy to treat irresectable liver tumors. Ann Surg. 2000;232:777-85.

62. Regimbeau JM, Cosse C, Kaiser G, Hubert C, Laurent C, Lapointe R, Isoniemi H, Adam R. Feasibility, safety and efficacy of two-stage hepatectomy for bilobar liver metastases of colorectal cancer: a LiverMetSurvey analysis. HPB (Oxford). 2017;19:396-405.

63. Wicherts DA, Miller R, De Haas RJ, Bitsakou G, Vibert E, Veilhan LA, Azoulay D, Bismuth H, Castaing D, Adam R. Longterm results of two-stage hepatectomy for irresectable colorectal cancer liver metastases. Ann Surg. 2008;248:994-1005.

64. Schnitzbauer AA, Lang SA, Goessmann H, Nadalin S, Baumgart J, Farkas SA, Fichtner-Feigl S, Lorf T, Goralcyk A, Horbelt R, Kroemer A, Loss M, Rummele P, Scherer MN, Padberg W, Konigsrainer A, Lang H, Obed A, Schlitt HJ. Right portal vein ligation combined with in situ splitting induces rapid left lateral liver lobe hypertrophy enabling 2-staged extended right hepatic resection in small-for-size settings. Ann Surg. 2012;255:405-14.

65. Enne M, Schadde E, Bjornsson B, Hernandez Alejandro R, Steinbruck K, Viana E, Campos RR, Malago M, Clavien PA, De Santibanes E, Gayet B. ALPPS as a salvage procedure after 
insufficient future liver remnant hypertrophy following portal vein occlusion. HPB (Oxford). 2017;19:1126-9.

66. Moris D, Ronnekleiv-Kelly S, Kostakis ID, Tsilimigras DI, Beal EW, Papalampros A, Dimitroulis D, Felekouras E, Pawlik TM. Operative results and oncologic outcomes of associating liver partition and portal vein ligation for staged hepatectomy (ALPPS) versus two-stage hepatectomy (TSH) in patients with unresectable colorectal liver metastases: a systematic review and meta-analysis. World J Surg. 2018;42:806-15.

67. Adam R, Imai K, Castro Benitez C, Allard MA, Vibert E, Cunha AS, Cherqui D, Baba H, Castaing D. Outcome after associating liver partition and portal vein ligation for staged hepatectomy and conventional two-stage hepatectomy for colorectal liver metastases. Br J Surg. 2016;103:1521-9.

68. Adam R, Delvart V, Pascal G, Valeanu A, Castaing D, Azoulay D, Giacchetti S, Paule B, Kunstlinger F, Ghemard O, Levi F, Bismuth $\mathrm{H}$. Rescue surgery for unresectable colorectal liver metastases downstaged by chemotherapy: a model to predict long-term survival. Ann Surg. 2004;240:644-57; discussion 57-8.

69. Adam R, De Gramont A, Figueras J, Guthrie A, Kokudo N, Kunstlinger F, Loyer E, Poston G, Rougier P, Rubbia-Brandt L, Sobrero A, Tabernero J, Teh C, Van Cutsem E. The oncosurgery approach to managing liver metastases from colorectal cancer: a multidisciplinary international consensus. Oncologist. 2012;17:1225-399.

70. Chun YS, Vauthey JN, Boonsirikamchai P, Maru DM, Kopetz S, Palavecino M, Curley SA, Abdalla EK, Kaur H, Charnsangavej C, Loyer EM. Association of computed tomography morphologic criteria with pathologic response and survival in patients treated with bevacizumab for colorectal liver metastases. JAMA. 2009;302:2338-444.

71. Falcone A, Ricci S, Brunetti I, Pfanner E, Allegrini G, Barbara C, Crino L, Benedetti G, Evangelista W, Fanchini L, Cortesi E, Picone V, Vitello S, Chiara S, Granetto C, Porcile G, Fioretto L, Orlandini C, Andreuccetti M, Masi G. Phase III trial of infusional fluorouracil, leucovorin, oxaliplatin, and irinotecan (FOLFOXIRI) compared with infusional fluorouracil, leucovorin, and irinotecan (FOLFIRI) as first-line treatment for metastatic colorectal cancer: the Gruppo Oncologico Nord Ovest. J Clin Oncol. 2007;25:1670-6.

72. Bokemeyer C, Bondarenko I, Makhson A, Hartmann JT, Aparicio J, De Braud F, Donea S, Ludwig H, Schuch G, Stroh C, Loos AH, Zubel A, Koralewski P. Fluorouracil, leucovorin, and oxaliplatin with and without cetuximab in the first-line treatment of metastatic colorectal cancer. J Clin Oncol. 2009;27:663-71.

73. Folprecht G, Gruenberger T, Bechstein WO, Raab HR, Lordick F, Hartmann JT, Lang H, Frilling A, Stoehlmacher J, Weitz J, Konopke R, Stroszczynski C, Liersch T, Ockert D, Herrmann T, Goekkurt E, Parisi F, Kohne CH. Tumour response and secondary resectability of colorectal liver metastases following neoadjuvant chemotherapy with cetuximab: the CELIM randomised phase 2 trial. Lancet Oncol. 2010;11:38-47.

74. Garufi C, Torsello A, Tumolo S, Ettorre GM, Zeuli M, Campanella C, Vennarecci G, Mottolese M, Sperduti I, Cognetti F. Cetuximab plus chronomodulated irinotecan, 5-fluorouracil, leucovorin and oxaliplatin as neoadjuvant chemotherapy in colorectal liver metastases: POCHER trial. Br J Cancer. 2010;103:1542-7.

75. Carrato A, Abad A, Massuti B, Gravalos C, Escudero P, LongoMunoz F, Manzano JL, Gomez A, Safont MJ, Gallego J, GarciaParedes B, Pericay C, Duenas R, Rivera F, Losa F, ValladaresAyerbes M, Gonzalez E, Aranda E. First-line panitumumab plus FOLFOX4 or FOLFIRI in colorectal cancer with multiple or unresectable liver metastases: a randomised, phase II trial (PLANET-TTD). Eur J Cancer. 2017;81:191-202.

76. Wong R, Cunningham D, Barbachano Y, Saffery C, Valle J, Hickish T, Mudan S, Brown G, Khan A, Wotherspoon A, Strimpakos
AS, Thomas J, Compton S, Chua YJ, Chau I. A multicentre study of capecitabine, oxaliplatin plus bevacizumab as perioperative treatment of patients with poor-risk colorectal liveronly metastases not selected for upfront resection. Ann Oncol. 2011;22:2042-8.

77. Loupakis F, Cremolini C, Masi G, Lonardi S, Zagonel V, Salvatore L, Cortesi E, Tomasello G, Ronzoni M, Spadi R, Zaniboni A, Tonini G, Buonadonna A, Amoroso D, Chiara S, Carlomagno C, Boni C, Allegrini G, Boni L, Falcone A. Initial therapy with FOLFOXIRI and bevacizumab for metastatic colorectal cancer. N Engl J Med. 2014;371:1609-18.

78. Gruenberger T, Bridgewater J, Chau I, Alfonso PG, Rivoire M, Mudan S, Lasserre S, Hermann F, Waterkamp D, Adam R. Bevacizumab plus mFOLFOX-6 or FOLFOXIRI in patients with initially unresectable liver metastases from colorectal cancer: the OLIVIA multinational randomised phase II trial. Ann Oncol. 2015;26:702-8.

79. Pietrantonio F, Cremolini C, Petrelli F, Di Bartolomeo M, Loupakis F, Maggi C, Antoniotti C, De Braud F, Falcone A, Iacovelli R. First-line anti-EGFR monoclonal antibodies in panRAS wild-type metastatic colorectal cancer: a systematic review and meta-analysis. Crit Rev Oncol Hematol. 2015;96:156-66.

80. Van Cutsem E, Kohne CH, Lang I, Folprecht G, Nowacki MP, Cascinu S, Shchepotin I, Maurel J, Cunningham D, Tejpar S, Schlichting M, Zubel A, Celik I, Rougier P, Ciardiello F. Cetuximab plus irinotecan, fluorouracil, and leucovorin as first-line treatment for metastatic colorectal cancer: updated analysis of overall survival according to tumor KRAS and BRAF mutation status. J Clin Oncol. 2011;29:2011-9.

81. Douillard JY, Siena S, Cassidy J, Tabernero J, Burkes R, Barugel M, Humblet Y, Bodoky G, Cunningham D, Jassem J, Rivera F, Kocakova I, Ruff P, Blasinska-Morawiec M, Smakal M, Canon JL, Rother M, Oliner KS, Tian Y, Xu F, Sidhu R. Final results from PRIME: randomized phase III study of panitumumab with FOLFOX4 for first-line treatment of metastatic colorectal cancer. Ann Oncol. 2014;25:1346-55.

82. Heinemann V, Von Weikersthal LF, Decker T, Kiani A, VehlingKaiser U, Al-Batran SE, Heintges T, Lerchenmuller C, Kahl C, Seipelt G, Kullmann F, Stauch M, Scheithauer W, Hielscher J, Scholz M, Muller S, Link H, Niederle N, Rost A, Hoffkes HG, Moehler M, Lindig RU, Modest DP, Rossius L, Kirchner T, Jung A, Stintzing S. FOLFIRI plus cetuximab versus FOLFIRI plus bevacizumab as first-line treatment for patients with metastatic colorectal cancer (FIRE-3): a randomised, open-label, phase 3 trial. Lancet Oncol. 2014;15:1065-75.

83. Venook AP, Niedzwiecki D, Lenz H-J, Innocenti F, Mahoney MR, O'Neil BH, Shaw JE, Polite BN, Hochster HS, Atkins JN, Goldberg RM, Mayer RJ, Schilsky RL, Bertagnolli MM, Blanke CD. CALGB/SWOG 80405: phase III trial of irinotecan/5FU/leucovorin (FOLFIRI) or oxaliplatin/5-FU/leucovorin (mFOLFOX6) with bevacizumab (BV) or cetuximab (CET) for patients (pts) with KRAS wild-type (wt) untreated metastatic adenocarcinoma of the colon or rectum (MCRC). J Clin Oncol. 2014;32:LBA3.

84. Saltz LB, Clarke S, Diaz-Rubio E, Scheithauer W, Figer A, Wong R, Koski S, Lichinitser M, Yang TS, Rivera F, Couture F, Sirzen F, Cassidy J. Bevacizumab in combination with oxaliplatin-based chemotherapy as first-line therapy in metastatic colorectal cancer: a randomized phase III study. J Clin Oncol. 2008;26:2013-9.

85. Xu Q, Xu AT, Zhu MM, Tong JL, Xu XT, Ran ZH. Predictive and prognostic roles of BRAF mutation in patients with metastatic colorectal cancer treated with anti-epidermal growth factor receptor monoclonal antibodies: a meta-analysis. J Dig Dis. 2013;14:409-16. 
86. Arnold D, Lueza B, Douillard JY, Peeters M, Lenz HJ, Venook A, Heinemann V, Van Cutsem E, Pignon JP, Tabernero J, Cervantes A, Ciardiello F. Prognostic and predictive value of primary tumour side in patients with RAS wild-type metastatic colorectal cancer treated with chemotherapy and EGFR directed antibodies in six randomized trials. Ann Oncol. 2017;28:1713-29.

87. Ruers T, Van Coevorden F, Punt CJ, Pierie JE, Borel-Rinkes I, Ledermann JA, Poston G, Bechstein W, Lentz MA, Mauer M, Folprecht G, Van Cutsem E, Ducreux M, Nordlinger B. Local treatment of unresectable colorectal liver metastases: results of a randomized phase II trial. J Natl Cancer Inst. 2017;109. https ://doi.org/10.1093/jnci/djx015

88. Bhutiani N, Akinwande O, Martin RC. Efficacy and toxicity of hepatic intra-arterial drug-eluting (Irinotecan) bead (DEBIRI) therapy in irinotecan-refractory unresectable colorectal liver metastases. World J Surg. 2016;40:1178-90.

89. Liu DM, Thakor AS, Baerlocher M, Alshammari MT, Lim $\mathrm{H}$, Kos S, Kennedy AS, Wasan H. A review of conventional and drug-eluting chemoembolization in the treatment of colorectal liver metastases: principles and proof. Future Oncol. 2015;11:1421-8.

90. Rao PP, Pascale F, Seck A, Auperin A, Drouard-Troalen L, Deschamps F, Teriitheau C, Paci A, Denys A, Bize P, De Baere T. Irinotecan loaded in eluting beads: preclinical assessment in a rabbit VX2 liver tumor model. Cardiovasc Interv Radiol. 2012;35:1448-599.

91. Fiorentini G, Aliberti C, Tilli M, Mulazzani L, Graziano F, Giordani P, Mambrini A, Montagnani F, Alessandroni P, Catalano V, Coschiera P. Intra-arterial infusion of irinotecan-loaded drug-eluting beads (DEBIRI) versus intravenous therapy (FOLFIRI) for hepatic metastases from colorectal cancer: final results of a phase III study. Anticancer Res. 2012;32:1387-95.

92. Martin RC, Scoggins CR, Schreeder M, Rilling WS, Laing CJ, Tatum CM, Kelly LR, Garcia-Monaco RD, Sharma VR, Crocenzi TS, Strasberg SM. Randomized controlled trial of irinotecan drug-eluting beads with simultaneous FOLFOX and bevacizumab for patients with unresectable colorectal liver-limited metastasis. Cancer. 2015;121:3649-58.

93. Akinwande O, Dendy M, Ludwig JM, Kim HS. Hepatic intraarterial injection of irinotecan drug eluting beads (DEBIRI) for patients with unresectable colorectal liver metastases: a systematic review. Surg Oncol. 2017;26:268-75.

94. Cosimelli M, Golfieri R, Cagol PP, Carpanese L, Sciuto R, Maini CL, Mancini R, Sperduti I, Pizzi G, Diodoro MG, Perrone M, Giampalma E, Angelelli B, Fiore F, Lastoria S, Bacchetti S, Gasperini D, Geatti O, Izzo F. Multi-centre phase II clinical trial of yttrium-90 resin microspheres alone in unresectable, chemotherapy refractory colorectal liver metastases. Br J Cancer. 2010;103:324-31.

95. Hendlisz A, Van den Eynde M, Peeters M, Maleux G, Lambert B, Vannoote J, De Keukeleire K, Verslype C, Defreyne L, Van Cutsem E, Delatte P, Delaunoit T, Personeni N, Paesmans M, Van Laethem JL, Flamen P. Phase III trial comparing protracted intravenous fluorouracil infusion alone or with yttrium-90 resin microspheres radioembolization for liver-limited metastatic colorectal cancer refractory to standard chemotherapy. J Clin Oncol. 2010;28:3687-94.

96. Aranda E, Aparicio J, Bilbao JI, Garcia-Alfonso P, Maurel J, Rodriguez J, Sangro B, Vieitez JM, Feliu J. Recommendations for SIR-spheres Y-90 resin microspheres in chemotherapyrefractory/intolerant colorectal liver metastases. Future Oncol. 2017;13:2065-82.

97. Kennedy AS, Ball D, Cohen SJ, Cohn M, Coldwell DM, Drooz A, Ehrenwald E, Kanani S, Rose SC, Nutting CW, Moeslein FM, Savin MA, Schirm S, Putnam SG, Sharma NK, Wang EA. Multicenter evaluation of the safety and efficacy of radioembolization in patients with unresectable colorectal liver metastases selected as candidates for (90)Y resin microspheres. J Gastrointest Oncol. 2015;6:134-42.

98. Van den Hoven AF, Rosenbaum CE, Elias SG, De Jong HW, Koopman M, Verkooijen HM, Alavi A, Van den Bosch MA, Lam MG. Insights into the dose-response relationship of radioembolization with resin 90 Y-microspheres: a prospective cohort study in patients with colorectal cancer liver metastases. J Nucl Med. 2016;57:1014-9.

99. Van Hazel GA, Heinemann V, Sharma NK, Findlay MP, Ricke J, Peeters M, Perez D, Robinson BA, Strickland AH, Ferguson T, Rodriguez J, Kroning H, Wolf I, Ganju V, Walpole E, Boucher E, Tichler T, Shacham-Shmueli E, Powell A, Eliadis P, Isaacs R, Price D, Moeslein F, Taieb J, Bower G, Gebski V, Van Buskirk M, Cade DN, Thurston K, Gibbs P. SIRFLOX: randomized phase III trial comparing first-line mFOLFOX6 (plus or minus bevacizumab) versus mFOLFOX6 (plus or minus bevacizumab) plus selective internal radiation therapy in patients with metastatic colorectal cancer. J Clin Oncol. 2016;34:1723-31.

100. Wasan HS, Gibbs P, Sharma NK, Taieb J, Heinemann V, Ricke J, Peeters M, Findlay M, Weaver A, Mills J, Wilson C, Adams R, Francis A, Moschandreas J, Virdee PS, Dutton P, Love S, Gebski V, Gray A, van Hazel G, Sharma RA. First-line selective internal radiotherapy plus chemotherapy versus chemotherapy alone in patients with liver metastases from colorectal cancer (FOXFIRE, SIRFLOX, and FOXFIRE-Global): a combined analysis of three multicentre, randomised, phase 3 trials. Lancet Oncol. 2017;18:1159-71.

101. Van Hazel G, Heinemann V, Sharma N, Taieb J, Ricke J, Peeters M, Findlay M, Gibbs P. LBA-006Impact of primary tumour location on survival in patients with metastatic colorectal cancer receiving selective internal radiation therapy and chemotherapy as first-line therapy. Ann Oncol. 2017;28(mdx302):005.

102. Hammill CW, Billingsley KG, Cassera MA, Wolf RF, Ujiki MB, Hansen PD. Outcome after laparoscopic radiofrequency ablation of technically resectable colorectal liver metastases. Ann Surg Oncol. 2011;18:1947-54.

103. Littrup PJ, Aoun HD, Adam B, Krycia M, Prus M, Shields A. Percutaneous cryoablation of hepatic tumors: long-term experience of a large U.S. series. Abdom Radiol (NY). 2016;41:767-80.

104. Bala MM, Riemsma RP, Wolff R, Kleijnen J. Cryotherapy for liver metastases. Cochrane Database Syst Rev. 2013:CD009058. https://doi.org/10.1002/14651858.CD009058.pub2

105. Niessen C, Thumann S, Beyer L, Pregler B, Kramer J, Lang S, Teufel A, Jung EM, Stroszczynski C, Wiggermann P. Percutaneous irreversible electroporation: long-term survival analysis of 71 patients with inoperable malignant hepatic tumors. Sci Rep. 2017;7:43687.

106. Cohen EI, Field D, Lynskey GE, Kim AY. Technology of irreversible electroporation and review of its clinical data on liver cancers. Expert Rev Med Devices. 2018;15:99-106.

107. Joo JH, Park JH, Kim JC, Yu CS, Lim SB, Park IJ, Kim TW, Hong YS, Kim KP, Yoon SM, Park J, Kim JH. Local control outcomes using stereotactic body radiation therapy for liver metastases from colorectal cancer. Int J Radiat Oncol Biol Phys. 2017;99:876-83.

108. Orsi F, Zhang L, Arnone P, Orgera G, Bonomo G, Vigna PD, Monfardini L, Zhou K, Chen W, Wang Z, Veronesi U. Highintensity focused ultrasound ablation: effective and safe therapy for solid tumors in difficult locations. AJR Am J Roentgenol. 2010;195:W245-W252252.

Publisher's Note Springer Nature remains neutral with regard to jurisdictional claims in published maps and institutional affiliations. 